\title{
Effect of chamomile on chemotherapy-induced neutropenia: a pilot open-label controlled trial
}

\author{
MAHDI SHAHRIARI ${ }^{1}$, MOHAMMAD AZADBAKHT ${ }^{2}$, MARYAM ROOHPARVAR ${ }^{3}$, BABAK DANESHFARD ${ }^{4}$, MAJID \\ NIMROUZI $5,6 *$ \\ ${ }^{1}$ Hematology Research Center, Namazi Hospital, Shiraz University of Medical Sciences, Shiraz, Iran. \\ ${ }^{2}$ Department of Pharmacognosy, Faculty of Pharmacy, Mazandaran University of Medical Sciences, Sari, Iran. \\ ${ }^{3}$ Jahrom University of Medical Sciences, Jahrom, Iran. \\ ${ }^{4}$ Integrative Medicine Research Unit, Chronic Respiratory Diseases Research Center, National Research Institute of Tuberculosis and Lung \\ Diseases (NRITLD), Shahid Beheshti University of Medical Sciences, Tehran, Iran. \\ ${ }^{5}$ Research Center for Traditional Medicine and History of Medicine, Shiraz University of Medical Sciences, Shiraz, Iran. \\ ${ }^{6}$ Department of Persian Medicine, School of Medicine, Shiraz University of Medical Sciences, Shiraz, Iran. \\ ${ }^{*}$ Corresponding author: Majid Nimrouzi, MD, MPH, PhD, Imam Hossein square, School of Medicine, Department of Persian Medicine, \\ Shiraz 7134845794, Iran. E-mail: nimruzim@sums.ac.ir.Tel/Fax: +987132345145.
}

\begin{abstract}
Neutropenia is a common complication of chemotherapy in leukemic patients. An herbal formulation of chamomile was hypothesized to be effective on neutropenia. A group of healthy volunteers and two groups of patients received chamomile oral drop to be compared with a control group of neutropenic patients. Results showed an increase of white blood cells and resolution of neutropenia in all groups except for the control group. In conclusion, chamomile could be used as an effective complementary medicine for increasing the immunity of neutropenic patients (in addition to healthy individuals).
\end{abstract}

Keywords: Chamomile; Leukemia; Chemotherapy; Neutropenia; Integrative Medicine; Persian Medicine

\section{INTRODUCTION}

Neutropenia is a blood disorder defined by a decrease in the absolute neutrophilic count (ANC) below normal range. It is categorized into three types of mild (1000 cells/ $\mu$ l $\leq$ ANC $<1500$ cells $/ \mu$ l), moderate $(500$ cells $/ \mu \mathrm{l} \leq$ ANC $\leq 1000$ cells $/ \mu \mathrm{l})$ and sever $(\mathrm{ANC}<500$ cells/ $/ \mathrm{ll})(1,2)$. The disorder is also associated with susceptibility to serious bacterial and fungal infections which sometimes are life threatening (3).

Although congenital or cyclic neutropenia is rarely seen in normal population, its occurrence is very common after chemotherapy for malignancies (2). The standard treatment protocol for neutropenia which is became available in last decades is consisted of Granulocyte Colony-stimulating Factor (G-CSF) and GranulocyteMonocyte Colony-Stimulating Factor (GM-CSF). Regardless of the effectiveness, their price is extremely high.

Persian medicine (PM) is a holistic medical system based on diagnosis of temperament (4). It is a great reservoir of clinical experiences which provides valorous nutritional and herbal recommendations for treatment of different types of the diseases $(5,6)$.

According to PM sources, children comprise a vulnerable group to develop diseases because they are in the growing age and usually do not have the healthy patterns of eating and drinking (7). They usually possess hot-wet temperament and consequently are more prone to develop wet-tempered diseases; that is the reason why usually hot-dry nutritional and herbal formulations are considered for treatment of children's illnesses $(8,9)$.

Chamomile is an annual plant commonly used in Iranian folk medicine for variety of diseases and cited in many sources of PM including Avicenna's canon of medicine (9). A number of its clinical applications have also been investigated through evidence-based studies and clinical trials (10-12). It is a hot-dry tempered herbal medicine with a wide range of medical properties including maturating, fiddling away the stagnated moistures, and banning the reabsorption of the morbid matters with strengthening the affected organs (9).

Matricaria chamomilla (Asteraceae), also called Baboone Shirazi in Persian medicine literature, is a globally used medicinal herb with a wide range of application (13). Its dried flower has been used as a sedative and spasmolytic agent (14). Apigenin as one of the main components of chamomile is an anti-inflammatory agent which suppresses prostaglandin E2 $(15,16)$. Moreover, it plays an anxiolytic role by reducing GABA-activated chloride currents (14). Also, chrysin as a flavenoid possess anxiolytic effects (17). Chamomile contains high amounts of bisabolol oxide A, bisabolol oxide $B$, and chamazulene (18). In-vitro studies showed free radical scavenging and antioxidant activities of the chamomile's essential oil (18).

Additionally, apigenin has shown anti-cancer effects in human cell lines (19) making chamomile a safe affordable anti-cancer agent (20). Dosage of chamomile in children is $0.3-0.6 \mathrm{~g}$ of dried flower, while in adolescents and adults is considered to be $0.8-24 \mathrm{~g}$ of dried flower (21).

According to aforementioned properties of chamomile, we conducted a pilot prospective clinical study to evaluate the efficacy of chamomile drop in treatment of neutropenia.

\section{MATERIALS AND METHODS}

Fifteen healthy volunteer students (aged 19-24 years) as group 1 and 70 children (aged 2-15 years) with chemotherapy-induced neutropenia were enrolled in the study. These children were divided into two groups by random allocation [i.e., 35 persons in the case group (group two) and 35 persons in the control group (group three)]. Also, three children with congenital neutropenia and three children with cyclic neutropenia (group four) were included. 
Chamomile oral drop (prepared by Amin drug company, Isfahan, Iran) was prescribed for the participants of group one, two, and four in a dose of 20 drops three times a day (each one milliliter contains $0.1 \mathrm{mg}$ chamazolen and $0.02 \mathrm{mg}$ Apigenin) for two weeks. It is to be noticed that all leukemic patients were receiving their chemotherapy regiments and chamomile drop was used as a complementary therapy. White blood cells (WBC) and ANC as the outcome measures were checked before and after intervention.

As for the data analysis, we used analysis of variances which was applied by EPI software and p-value less than 0.05 considered as statistical significance.

\section{RESULTS}

The changes of white blood cell (WBC) and absolute neutrophil count (ANC) of the groups has been illustrated in Table 1. Significant increase of WBC was seen in all groups except for control group (group 3). Additionally, although a significant increase of ANC was seen in all groups, however, resolution of neutropenia did not happen in the control group despite other groups which were not neutropenic at the end of the intervention. It is also to be mentioned that no adverse reaction was seen in the period of intervention.

\section{DISCUSSION}

Effect of plants on human health has been documented for thousands of years (21-25). Herbal drugs have been integral to both traditional and non-traditional medicine in the last 5000 years $(22,26-28)$. The cause of popularity of herbal medicines can be explained by their tendency to work slowly with minimal toxic side effects. As a traditional medicine both in Asia and in Europe, it is used to treat wounds, ulcers, eczema, gout, skin irritations, bruises, burns, canker sores, neuralgia, sciatica, rheumatic pain, hemorrhoids, mastitis and other ailments (13).

Chamomile has been used to treat inflammations of the skin and mucous membranes, and also for some bacterial infections of the skin, oral cavity and gums, and respiratory tract. Aqueous Extract of Chamomile has been frequently used as a mild sedative to calm nerves and reduce anxiety, to treat hysteria, nightmares, insomnia and other sleep problems $(13,29)$.

Anticancer activity and tumor growth inhibition by chamomile has been evaluated in studies with apigenin which is one of the bioactive constituents of chamomile. Studies on preclinical models of skin, prostate, breast and ovarian cancer have shown promising growth inhibitory effects $(30,31)$. In a recently conducted study, chamomile extracts were shown to cause minimal growth inhibitory effects on normal cells, but showed significant reductions in cell viability in various human cancer cell lines. Chamomile exposure induced apoptosis in cancer cells but not in normal cells at similar doses (19). The efficacy of the novel agent TBS-101, a mixture of seven standardized botanical extracts including chamomile has been recently tested. The results confirm it to have a good safety profile with significant anticancer activities against androgen-refractory human prostate cancer PC-3 cells, both in vitro and in vivo situation (32).
Treatment of neutropenia for preventing serious and sometimes lethal bacterial and fungal infection with recombinant human cytokines like G-CSF and GM-CSF is useful but is very expensive and is associated with some complications including chills, fever, bone pain, and splenomegaly.

Matricaria chamomilla has been previously used for prevention and treatment of chemotherapy/radiotherapy induced stomatitis by our research group (unpublished data which were presented in $8^{\text {th }}$ International Congress of Geographic Medicine, Shiraz, Iran).

Its corticosteroid-like effect which is between hydrocortisone and prednisolone is not the cause of this effect of the drug on the neutrophil count because all the patients in the chemotherapy-induced neutropenia (case and control) were receiving prednisolone for four weeks in their protocol of chemotherapy for Acute Lymphocytic Leukemia.

\section{CONCLUSION}

In conclusion, low cost, absence of adverse reactions and safety of its use during the course of chemotherapy makes chamomile a superior drug in the treatment of neutropenia. However, its mechanism of action and clinical effects should be investigated through further rigorous studies.

Acknowledgment: This paper was derived from thesis written by Maryam Roohparvar as a part of fulfilment in doctor of Pharmacy and supported by Research Affair of Shiraz University of Medical Sciences.

\section{REFERENCES}

1. Tefferi A. Primary hematology: Springer Science \& Business Media; 2000.

2. Boxer L, Dale DC. Neutropenia: Causes and consequences. Seminars in Hematology. 2002;39(2):75-81.

3. Eisen DP, Minchinton RM. Impact of mannose-binding lectin on susceptibility to infectious diseases. Clinical Infectious Diseases. 2003;37(11):1496-505.

4. Atarzadeh F, Daneshfard B, Dastgheib L, Jaladat A, Amin G. Early Description of Diet-Induced Blistering Skin Diseases in Medieval Persia: Avicenna's Point of View. Skinmed. 2016;14(5):367-70.

5. Nimrouzi M, Daneshfard B, Tafazoli V, Akrami R. Insomnia in Traditional Persian Medicine. Acta medico-historica Adriatica. 2019;17(1):45-54.

6. Nimrouzi M, Zare M. Principles of nutrition in Islamic and traditional Persian medicine. Journal of evidence-based complementary \& alternative medicine. 2014;19(4):267-70.

7. Nimrouzi M, Zarshenas MM. Functional constipation in children: non-pharmacological approach. Journal of integrative medicine. 2015;13(2):69-71.

8. Nimrouzi M, Sadeghpour O, Imanieh MH, Shams-Ardekani M, Zarshenas MM, Salehi A, et al. Remedies for children constipation in medieval Persia. Journal of evidence-based complementary \& alternative medicine. 2014;19(2):137-43.

9. Avicenna H. Ghanoon Dar Teb [The Canon of Medicine], Bulaq Edition. Sharafkandi A, trans Tehran: Univ of Tehran Pr. 1978.

10. Shoara R, Hashempur MH, Ashraf A, Salehi A, Dehshahri S, Habibagahi Z. Efficacy and safety of topical Matricaria chamomilla L.(chamomile) oil for knee osteoarthritis: a randomized controlled clinical trial. Complementary therapies in clinical practice. 2015;21(3):181-7.

11. Hashempur MH, Ghasemi MS, Daneshfard B, Ghoreishi PS, Lari ZN, Homayouni K, et al. Efficacy of topical chamomile oil for mild and moderate carpal tunnel syndrome: A 
randomized double-blind placebo-controlled clinical trial. Complementary Therapies in Clinical Practice. 2017;26:61-7.

12. Daneshfard $B$, Shahriari $M$, Heiran A, Nimrouzi $M$, Yarmohammadi $\mathrm{H}$. Effect of chamomile on chemotherapyinduced neutropenia in pediatric leukemia patients: A randomized triple-blind placebo-controlled clinical trial. Avicenna Journal of Phytomedicine. 2020 Jan;10(1):58-69.

13. Srivastava JK, Shankar E, Gupta S. Chamomile: A herbal medicine of the past with bright future. Molecular medicine reports. 2010;3(6):895.

14. Avallone R, Zanoli P, Puia G, Kleinschnitz M, Schreier P, Baraldi M. Pharmacological profile of apigenin, a flavonoid isolated from Matricaria chamomilla. Biochemical pharmacology. 2000;59(11):1387-94.

15. Avula B, Wang $\mathrm{Y}-\mathrm{H}$, Wang $\mathrm{M}$, Avonto $\mathrm{C}$, Zhao J, Smillie TJ, et al. Quantitative determination of phenolic compounds by UHPLC-UV-MS and use of partial least-square discriminant analysis to differentiate chemo-types of Chamomile/Chrysanthemum flower heads. Journal of Pharmaceutical and Biomedical Analysis. 2014;88:278-88.

16. Srivastava JK, Pandey M, Gupta S. Chamomile, a novel and selective COX-2 inhibitor with anti-inflammatory activity. Life sciences. 2009;85(19):663-9.

17. Zanoli $\mathrm{P}$, Avallone R, Baraldi M. Behavioral characterisation of the flavonoids apigenin and chrysin. Fitoterapia. 2000;71:S117-S23.

18. Roby MHH, Sarhan MA, Selim KA-H, Khalel KI. Antioxidant and antimicrobial activities of essential oil and extracts of fennel (Foeniculum vulgare L.) and chamomile (Matricaria chamomilla L.). Industrial crops and products. 2013;44:43745.

19. Srivastava JK, Gupta S. Antiproliferative and apoptotic effects of chamomile extract in various human cancer cells. Journal of agricultural and food chemistry. 2007;55(23):9470-8.

20. Hosseinpour M, Mobini-Dehkordi M, Teimori H. Quantitative Gene Expression of ERG9 in Model Saccharomyces cerevisiae: Chamomile Extract For Human Cancer Treatment. 2016.
21. Das M. Chamomile: medicinal, biochemical, and agricultural aspects: CRC Press; 2014.

22. Newman DJ, Cragg GM, Snader KM. Natural products as sources of new drugs over the period 1981-2002. Journal of natural products. 2003;66(7):1022-37.

23. Koehn FE, Carter GT. The evolving role of natural products in drug discovery. Nature reviews Drug discovery. 2005;4(3):206-20.

24. Golshani SA, Daneshfard B, Mosleh G, Salehi A. Drugs and pharmacology in the Islamic Middle Era. Pharm Hist (Lond). 2015;45(3):64-9.

25. Jabbari M, Daneshfard B, Emtiazy M, Khiveh A, Hashempur $\mathrm{MH}$. Biological Effects and Clinical Applications of Dwarf Elder (Sambucus ebulus L): A Review. Journal of evidencebased complementary \& alternative medicine. 2017;22(4):996-1001.

26. Philp RB. Herbal Remedies: The Good, The Bad, and The Ugly. Journal of Complementary and Integrative Medicine. 2006;1(1)

27. Fabricant DS, Farnsworth NR. The value of plants used in traditional medicine for drug discovery. Environmental health perspectives. 2001;109(Suppl 1):69.

28. Hadley SK, Petry JJ. Medicinal herbs: a primer for primary care. Hospital Practice. 1999;34(6):105-23.

29. Forster $\mathrm{H}$, Niklas $\mathrm{H}$, Lutz $\mathrm{S}$. Antispasmodic effects of some medicinal plants. Planta medica. 1980;40(12):309-19.

30. Way T-D, Kao M-C, Lin J-K. Apigenin induces apoptosis through proteasomal degradation of HER2/neu in HER2/neu-overexpressing breast cancer cells via the phosphatidylinositol 3-kinase/Akt-dependent pathway. Journal of biological chemistry. 2004;279(6):4479-89.

31. Birt D, Mitchell D, Gold B, Pour P, Pinch H. Inhibition of ultraviolet light induced skin carcinogenesis in $\mathrm{SKH}-1$ mice by apigenin, a plant flavonoid. Anticancer research. 1996;17(1A):85-91.

32. Evans S, Dizeyi N, Abrahamsson P-A, Persson J. The effect of a novel botanical agent TBS-101 on invasive prostate cancer in animal models. Anticancer research. 2009;29(10):3917-24.

Table 1. Changes of white blood cell and absolute neutrophil count in four groups of study before and after intervention.

\begin{tabular}{|c|c|c|c|c|c|c|c|c|}
\hline & \multicolumn{2}{|l|}{ Group 1} & \multicolumn{2}{|l|}{ Group 2} & \multicolumn{2}{|l|}{ Group 3} & \multicolumn{2}{|l|}{ Group 4} \\
\hline & $\begin{array}{l}\text { Before } \\
\text { intervention } \\
\text { (Mean } \pm S D)\end{array}$ & $\begin{array}{l}\text { After } \\
\text { intervention } \\
\text { (Mean } \pm S D \text { ) }\end{array}$ & $\begin{array}{l}\text { Before } \\
\text { intervention } \\
\text { (Mean } \pm S D \text { ) }\end{array}$ & $\begin{array}{l}\text { After } \\
\text { intervention } \\
\text { (Mean } \pm S D)\end{array}$ & $\begin{array}{l}\text { Before } \\
\text { intervention } \\
\text { (Mean } \pm S D)\end{array}$ & $\begin{array}{l}\text { After } \\
\text { intervention } \\
\text { (Mean } \pm S D)\end{array}$ & $\begin{array}{l}\text { Before } \\
\text { intervention } \\
\text { (Mean } \pm S D \text { ) }\end{array}$ & $\begin{array}{l}\text { After } \\
\text { intervention } \\
\text { (Mean } \pm S D)\end{array}$ \\
\hline $\begin{array}{l}\text { WBC } \\
\left(/ \mathrm{mm}^{3}\right)\end{array}$ & $7270+141$ & $7360+133$ & $1380+128$ & $4900+590$ & $2770+360$ & $2730+600$ & $3200+30.3$ & $4600+25.6$ \\
\hline P-Value & \multicolumn{2}{|l|}{$<0.01$} & \multicolumn{2}{|l|}{0.008} & \multicolumn{2}{|l|}{0.75} & \multicolumn{2}{|l|}{$<0.05$} \\
\hline $\begin{array}{l}\text { ANC } \\
(/ \mathrm{mm} 3)\end{array}$ & $4940 \pm 130$ & $5090 \pm 130$ & $63 \pm 9$ & $1600 \pm 308$ & $210 \pm 22$ & $400 \pm 42$ & $368+16.6$ & $1610+16.4$ \\
\hline P-Value & \multicolumn{2}{|l|}{$<0.0008$} & \multicolumn{2}{|l|}{0.008} & \multicolumn{2}{|l|}{0.026} & \multicolumn{2}{|l|}{$<0.05$} \\
\hline
\end{tabular}

WBC: white blood cell; ANC: absolute neutrophil count 